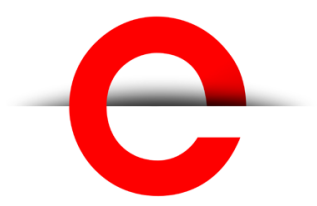

U T S

e PRES S
International Journal

of Rural Law and

Policy

No. 22017

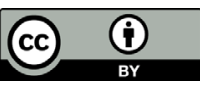

(c) 2017 The Author(s). This is an Open Access article distributed under the terms of the Creative Commons Attribution 4.0 Unported (CC BY 4.0) License (https:// creativecommons.org/ licenses/by/4.0/), allowing third parties to copy and redistribute the material in any medium or format and to remix, transform, and build upon the material for any purpose, even commercially, provided the original work is properly cited and states its license.

Citation: Bruno Spandonide, Sustainable Remote Australian Transport for Living on Country and Going Out Bush' (2017) 2 International Journal of Rural Law and Policy, Article ID 4941. http:// dx.doi.org/10.5130/ijrlp. i2.2017.4941

ISSN 1839-745x | Published by UTS ePRESS I http://ijrlp. epress.lib.uts.edu.au
ARTICLE

\section{Sustainable remote Australian transport for living on country and going out bush}

\author{
Bruno Spandonide \\ CRC for Remote Economic Participation, Ninti One, Flinders University, SA, Australia \\ Corresponding author: Bruno Spandonide, Flinders University, SA, Australia. \\ bruno.spandonideanintione.com.au
}

DOI: http://dx.doi.org/10.5130/ijrlp.i2.2017.4941

\begin{abstract}
Domestic and international academic literature analyses of links between transport and wellbeing focus mainly on urban settings and vulnerable population groups including older people, people with health issues, socioeconomically disadvantaged people, or people undergoing frequent and extreme climatic events. While the relationship between the wellbeing of remote Australians and travelling activities is evident, its complexity is an under-researched topic. This is paradoxical considering that extreme distances, high supply chain costs, and limited access to services and to economic participation are well recognised obstacles for sustaining vibrant remote Australian communities. Moreover, the latest accessibility-driven technological innovations in the digital and sharing economies are highly topical in transport projects in urban agglomerations but still a distant reality for remote Australia. There is a need to develop an appropriateness framework for such technologies because of their strong relevance to multiple outcomes in terms of wellbeing. Furthermore what defines a good quality of life between remote and urban contexts can sometimes be very similar but also very different. In the light of some recent transport and mobility research, this paper analyses the potential connections between more appropriate transport systems and innovations and the increased resilience of remote communities.
\end{abstract}

\section{Keywords}

transport, remote Australia, sustainability, wellbeing, livelihoods 


\section{Introduction}

Aboriginal and Torres Strait Islander people who live in remote areas face many challenges beyond those generally faced by non-Aboriginal and Torres Strait Islander people who live in urban areas. Many of the difficulties are connected with poor access to transport.

The purpose of this article is to explore how appropriate transport activities can promote wellbeing. The article begins by highlighting the specific needs for good transport in remote communities then discusses the links among transport and the social and cultural systems and processes that characterise the livelihoods of the 1200 Aboriginal and Torres Strait Islanders living in very remote communities.

The appropriateness of transport initiatives is examined in the light of a dedicated wellbeing framework. In order to provide practical examples, a model lists a few appropriate transport initiatives extrapolated from the responses of a transport survey and a mobility survey undertaken in remote communities around Central Australia; they are summarised and evaluated through the framework.

The conclusions of the paper will provide insights into the types of transport alternatives that would be the most likely to contribute to developing increasingly more resilient remote Aboriginal and Torres Strait Islander communities, and improving their wellbeing and sustainability.

\section{Remote Australian transport an oxymoron of sustainability?}

Living in remote Australia has been perceived as challenging for a long time. ${ }^{1}$ Generally, people agree that living in the Outback is tough, and economic and physical survival requires robust and reliable equipment, satellite telecommunications, and good air and land transport. ${ }^{2}$ The requirements of the remote Australian transport system, in particular, tend to converge towards highly unsustainable livelihoods by world standards. The most privileged remote Australians display some of the highest annual consumptions of fossil fuel per capita in the world for transport activities, with an average of seven tonnes of $\mathrm{CO}_{2}$ per person per year; this is around four times the average of OECD countries and almost 30 times sustainable levels. ${ }^{3}$ The reason for such a high consumption is that the relatively small number of people living in remote Australia needs to travel long distances through vast tracts of isolated areas. To do so, they rely heavily on large four wheel drive vehicles or need to travelby air. Both transport systems primarily rely on petroleum types of fossil fuels. ${ }^{4}$

Because Aboriginal and Torres Strait Islander people have been dislocated from their traditional country and cultural identities, and from accessing services and participating in the economy, ${ }^{5}$ a structural situation of physical, socio-economic and cultural isolation and marginality has developed. ${ }^{6}$ As a result, Aboriginal and Torres Strait Islander people comprise a larger proportion of the population in remote Australia than in urban areas, and access to good land and air transport equipment is unavailable for the vast majority. Indeed their transport storyline is vastly different to that of the privileged rest of Australia, with an average of ten times fewer vehicles per person, a fleet of old inappropriate vehicles, the need to travel over long stretches of unsealed roads, and effectively half of the population not having access to public transport or air transport at all. This narrative uncovers a rhetoric of sustainability based on radically different issues and relationships between wellbeing and transport. ${ }^{7}$ Spandonide has described the vast

\footnotetext{
1 G Gerard, "Everyone will be Jealous for that Mutika", Mankind (1989) 19(2) 95; R Lawrence, "Motorised Transportation in Remote Aboriginal Australia’ Australian Aboriginal Studies (1991) 262.

2 P Bishop, 'Off Road: Four-Wheel Drive and the Sense of Place' Environment and Planning D: Society and Space (1996) 14(3) 257; A Taylor and B Prideaux, "Profiling Four Wheel Drive Tourism Markets for Desert Australia", Journal of Vacation Marketing, 14(1) 71.

${ }^{3}$ N Holyoak, B Spandonide, B Stazic and R Zito, (2016), ‘Travelling in Remote Australia Might Come a Gutsa: An Extreme Case of Transport Carbon Vulnerability' Adelaide.

${ }^{4}$ Ibid.

${ }^{5}$ G Currie and Z Senbergs, 'Indigenous Communities: Transport Disadvantage and Aboriginal Communities' in Graham Currie, Janet Stanley and John Stanley (eds), No Way to Go: Transport and Social Disadvantage in Australian Communities (Monash University Press, Melbourne, 2007), 1-9,12.

${ }^{6} \mathrm{~J}$ Finlayson and A Auld, Shoe or Stew? Balancing Wants and Needs in Indigenous Households: A Study of Appropriate Income Support Payments and Policies for Families (Australian National University - Centre for Aboriginal Economic Policy Research, Canberra, ACT, 1999).

7 G Currie and A Delbosc, 'Exploring Transport Disadvantage, Social Exclusion and Well-Being in Spatial Context', (Paper presented at World Congess on Transport Research, $12^{\text {th }}$, Lisbon, Portugal, 2010).
} 
difference between the circumstances of the two groups of people (privileged and not privileged) living in remote communities as a two speed transport system ${ }^{8}$ which exacerbates socio-economic inequalities.

In this context, and from a transport point of view, social sustainability is related to concepts such as transport equity, liveability, community development, social justice and support, human rights, place making, cultural competence, community resilience, and human adaptation ${ }^{9}$. One of the main challenges, in terms of transport sciences, is the fact the transport crisis affecting remote Aboriginal and Torres Strait Islander communities remains particularly poorly understood from a socio-cultural perspective. ${ }^{10}$

\section{Relationship between transport and wellbeing}

The relationships between transport and wellbeing in the remote Australian context are evident in many ways. Transport provides opportunities for interacting with different environments, accessing goods, information and services, contributing to social networks and developing cultural activities, and enabling participating in economic activities (Fogarty 2005). ${ }^{11}$ In this sense, good transport can lead to better health outcomes, improved access to health services, positive social and community dynamics, and economic participation and productivity. ${ }^{12}$

\section{Transport and wellbeing in remote Australia}

The links between transport and livelihoods in remote Australia are particularly complex. Indeed, in remote Australia, transport is a major factor for a large set of livelihood elements with multiple levels of interconnection, as illustrated in Figure 1.

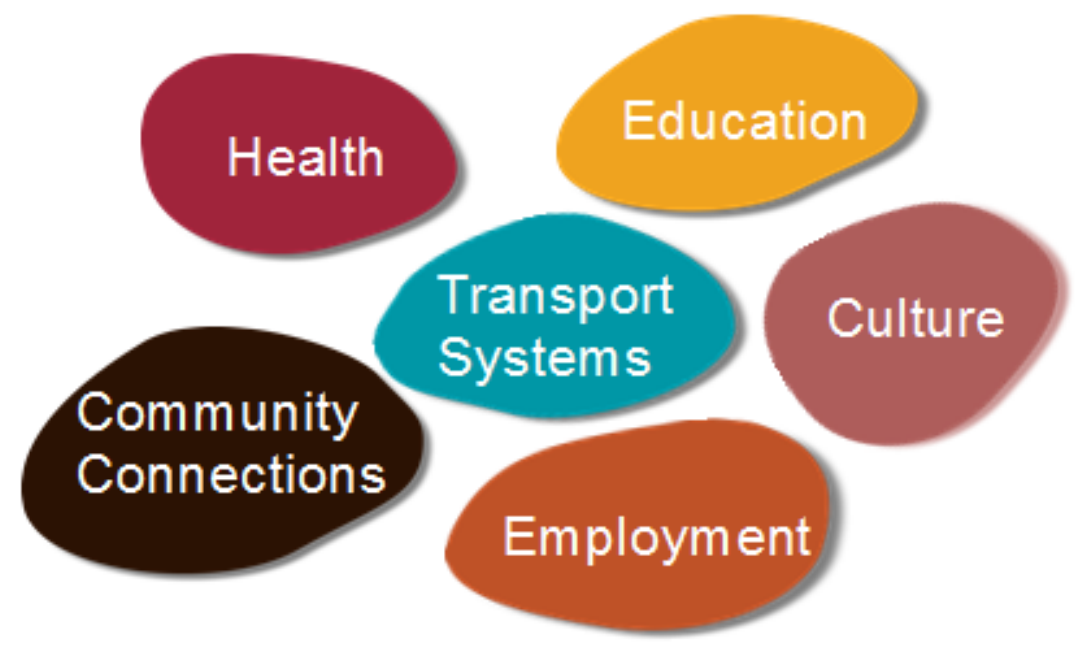

Figure 1: Links between transport and livelihoods in remote Australia

\footnotetext{
${ }^{8}$ B Spandonide, Transport Systems in Remote Australia: Transport Costs in Remote Communities (Ninti One Limited, Alice Springs. 2014).

9 R Costanza and B C Patten, ‘Defining and Predicting Sustainability’ Ecological Economics (1995) 15(3) 193; L Magee, A Scerri, P James, J Thom, L Padgham, S Hickmottt, H Deng and F Cahill, 'Reframing Social Sustainability Reporting: Towards an Engaged Approach' in Environment, Development and Sustainability: A multidisciplinary Approach to the Theory and Practice of Sustainable Development ( 2013) 15(1) 225.

${ }^{10}$ Currie and Senbergs, above n 5, 12; R Raicu, M Taylor, L Meng and G Currie, Scoping Study on Regional Transport in Desert Australia (Ninti One Limited, Alice Springs, 2011).

11 W Fogarty, "“You got any Truck?” Vehicles and Decentralised Mobile Service-Provision in Remote Indigenous Australia', (Centre for Aboriginal Economic Policy Research (CAEPR), ACT, Working Paper No. 30/2005, 2005).

12 T Litman, Transportation Cost and Benefit Analysis II (Victoria Transport Policy Institute Canada, 2013); T Litman and E Doherty, Transportation Cost and Benefit Analysis, Techniques, Estimates and Implications (Victoria Transport Policy Institute, Canada, 2011).
} 
In effect, the relative level of transport accessibility defines a certain level of ill or wellbeing. ${ }^{13}$ Contributors to ill and wellbeing that are often ignored include physical resources, social capital, relationships and other forms of human interaction, knowledge, experiences and networks. ${ }^{14}$

Given that access to good transport is an essential determinant of wellbeing, providing affordable and efficient transport is a fundamental way to reduce transport inaccessibility in areas which are physically isolated from the rest of the country. ${ }^{15}$ Improving remote transport systems can enable stronger social attributes and build a more positive sense of belonging to the wider community. The section goes on to focus on the appropriateness and the strengths of current transport systems and their potential for improving the liveability of remote communities, and outlines the transport impacts on wellbeing. The discussion also examines the dimension of appropriate transport in terms of reducing ill-being as a function of socio-economic disadvantage and socio-cultural injustice.

\section{Wellbeing in remote Australia}

III and wellbeing refer to the individual or collective conditions and quality of life, and include different forms of interrelated physical, cultural, psychological, social and economic elements. The two concepts of ill and wellbeing have been studied in Australia for more than 30 years, with the different sets of underlying causes extensively discussed. ${ }^{16}$ Figure 2 describes some of the individual types of wellbeing conceptualised by the Australian Bureau of Statistics that are specific to Aboriginal and Torres Strait Islander people. ${ }^{17}$

Nguyen and Cairney have developed a framework specific to the wellbeing of Aboriginal and Torres Strait Islander people (Nguyen and Cairney 2013), ${ }^{18}$ as illustrated in Figure 3.

The Nguyen and Cairney framework is the outcome of an extensive participatory study carried out by the authors and comprises six interconnected domains (culture, community, empowerment, education, employment and health).

A significant recent finding is that, in Aboriginal and Torres Strait Islander communities, socio-cultural and psychological forms of wellbeing are very important; that is, for Aboriginal and Torres Strait Islander remote community members, non-material forms of wellbeing are particularly significant. ${ }^{19}$ However, at present, for non-Aboriginal and Torres Strait Islander people living in remote Australia, economic forms of wellbeing as well as wellbeing related to accessing different types of services (housing, health, employment, education) tend to be over considered. ${ }^{20}$ In addition, even for innovative transport projects, advanced quadruple bottom line framework evaluations and methodologies are used as indicators with a predominant focus on dominant norms that correspond to economic forms of wellbeing ${ }^{21}$. Socio-cultural forms of wellbeing, however, can be effectively integrated into the evaluation of spin-off effects and the wider benefits of transport projects. ${ }^{22}$ Indeed, in the framework illustrated in Figure 3, the different forms

${ }^{13}$ Y Kinfu, Spatial Mobility Among Indigenous Australians: Patterns and Determinants (ANU Demography and Sociology Program, Research School of Social Sciences, Canberra, 2005); P Starkey, S Ellis, J Hine and A Ternel, Improving Rural Mobility: Options for Developing Motorized and Nonmotorized Transport in Rural Areas (World Bank, 2002).

${ }^{14}$ S Nutley, 'Indicators of Transport and Accessibility Problems in Rural Australia' Journal of Transport Geography (2003) 11(1) 55.

${ }^{15} \mathrm{G}$ Currie, J Stanley and J Stanley, No Way To Go: Transportation and Social Disadvantage in Australian Communities (Monash University ePress, 2007).

${ }^{16}$ B Headey, E Holmström and A Wearing, 'Well-Being and Ill-Being: Different Dimensions?' Social Indicators Research (1984), 14(2) 115.

${ }^{17}$ Australian Bureau of Statistics (ABS), 'Framework for Measuring Wellbeing: Aboriginal and Torres Strait Islander Peoples' (4703.0, 2010)

${ }^{18} \mathrm{O}$ K Nguyen and S Cairney, Literature Review of the Interplay between Education, Employment, Health and Wellbeing for Aboriginal and Torres Strait Islander People in Remote Areas Working Towards an Aboriginal and Torres Strait Islander Wellbeing Framework (Ninti One Limited, Alice Springs, 2013).

${ }^{19}$ M Dockery, 'Reconceptualising Mobility for Aboriginal and Torres Strait Islander Australians' (Working Paper CW015, CRC-REP, Alice Springs, 2014).

${ }^{20}$ A Morton and L Edwards, Community Wellbeing Indicators: Measures for Local Government (Australian Centre of Excellence for Local Government, University of Technology, Sydney, NSW, 2013).

${ }^{21}$ T Litman,' Well Measured: Developing Indicators for Sustainable and Livable Transport Planning' (Victoria Transport Policy Institute, 2016); T Litman, 'Evaluating Transportation Equity: Guidance for Incorporating Distributional Impacts in Transportation Planning' (Victoria Transport Policy Institute, 2017).

${ }^{22}$ B Spandonide, 'Understanding Transport Costs in Remote Australia' International Journal of Transport Economics (2016) XLIII. 
of wellbeing are highly inter-related; the authors suggest that wellbeing can be accurately defined and evaluated by studying appropriate indicators of the nature and degree of the integrated relationships. ${ }^{23}$

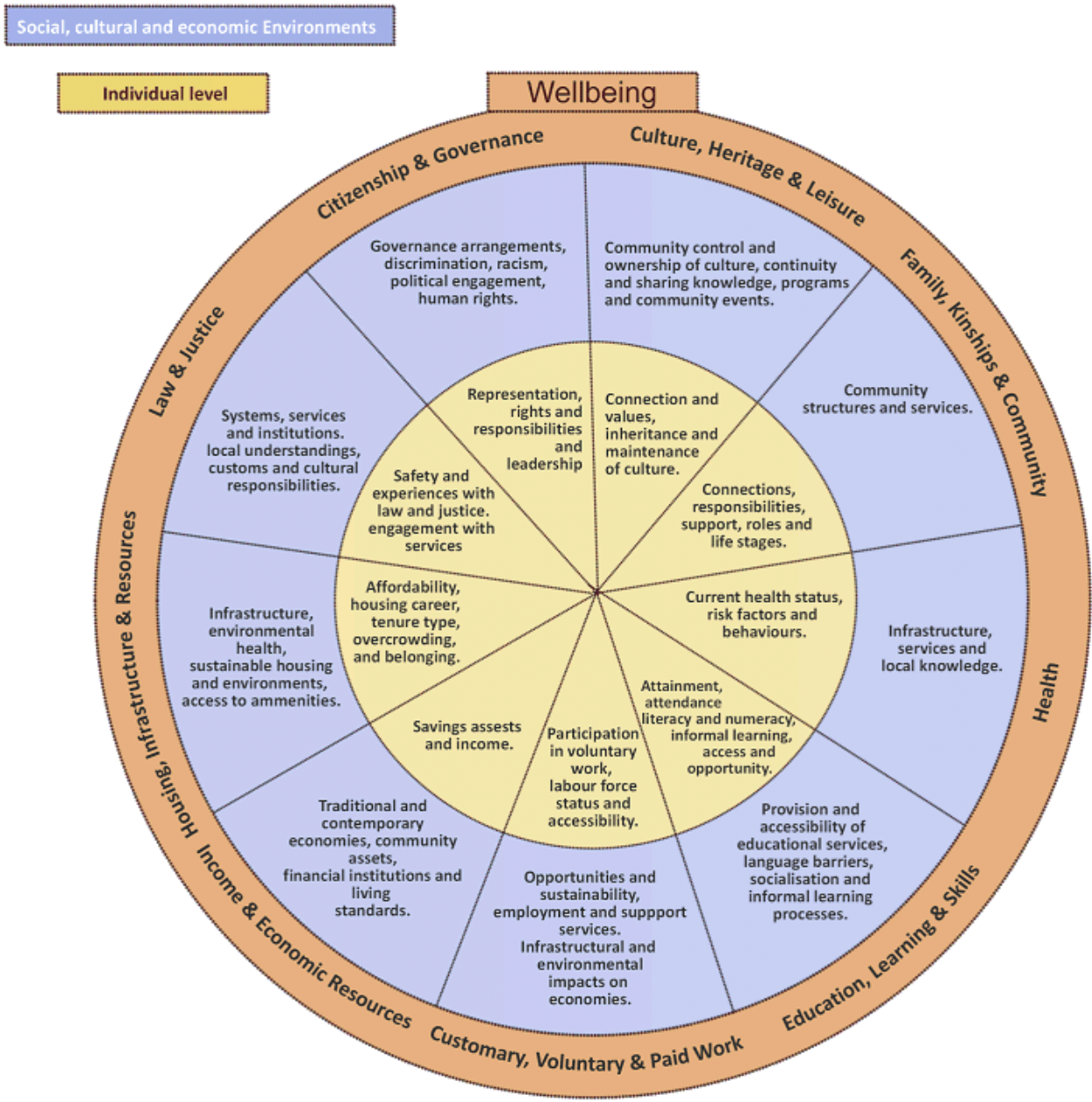

Figure 2: Framework for measuring wellbeing: Aboriginal and Torres Strait Islander people (Source: ABS, 4703.0, 2010)

Yet, for Aboriginal and Torres Strait Islander people living in remote Australia, while the elements of wellbeing that rely on accessing goods and services (such as health, housing, or transport services) are recognised, accessing goods and services are articulated around avoiding ill-being and are perceived as a decisive contributing factor of subjective wellbeing. ${ }^{24}$ The ABS notes that 'in 2008, 72 per cent of Torres Strait Islander people aged 15 years and over (adults) reported being a happy person all or most of the time, with rates higher among adults living in remote areas (78 per cent) than non-remote areas (71 per cent)'. ${ }^{25}$ Rates were also higher among adults living in the Torres Strait Indigenous Region (84 per cent) than elsewhere (70 per cent). This is the case even though remote Australian Aboriginal and Torres Strait Islander people have access to significantly fewer health, housing and transport services. ${ }^{26}$ That is, low well-being is not directly associated with specific places, and living in remote areas is generally linked with

\footnotetext{
${ }^{23}$ Nguyen and Cairney, above $\mathrm{n} 15$.

${ }^{24} \mathrm{~N}$ Biddle, 'Measures of Indigenous Wellbeing and Their Determinants Across the Lifecourse' in N Biddle (ed), Income, Work and Indigenous Livelihoods (Australian National University. Centre for Aboriginal Economic Policy Research, Lecture 5, 2011).

${ }^{25}$ ABS, Framework for Measuring, above $\mathrm{n} 16$.

${ }^{26}$ Australian Bureau of Statistics (ABS), Aboriginal and Torres Strait Islander People Public Transport Access (ABS, 2010); N Biddle, J Taylor and M Yap, 'Indigenous Participation in Regional Labour Markets, 2001-06' ( Centre for Aboriginal Economic Policy Research (CAEPR), ACT, Caepr Discussion Paper No. 288, 2008); J Taylor, 'The Spatial Context of Indigenous Service Delivery' (Centre for Aboriginal Economic Policy Research (CAEPR), ACT, CAEPR Working Paper No. 16 2002).
} 
higher levels of well-being. ${ }^{27}$ But low levels of well-being are associated with poorer health outcomes, and loss of family links and social support.

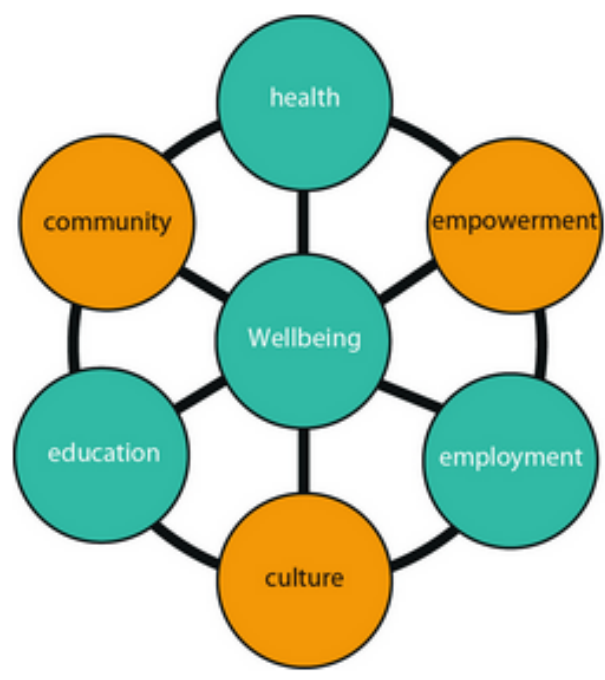

Figure 3: Framework specific to the wellbeing of Aboriginal and Torres Strait Islander people (source: Nguyen and Cairney, 2013)

Half of Aboriginal and Torres Strait Islander people aged 15 years and over had a disability or long-term health condition in 2008 and 8 per cent had a profound/severe core activity limitation. In non-remote areas, Aboriginal and Torres Strait Islander adults were one and a half times as likely as non-Indigenous adults to have a disability or long-term health condition, and more than twice as likely to have a profound/severe core activity limitation. ${ }^{28}$

Eight per cent of all Aboriginal and Torres Strait Islander adults reported having been removed from their natural family and 38 per cent had relatives that had been removed from their families. Furthermore, the ABS notes that 'people who were able to have a frequent say on community issues were more likely to report feeling happy all/most of the time than those with little or no input (81 per cent compared with 67 per cent)'. ${ }^{29}$ Employment was also a positive factor in reported rates of happiness, but income level was less correlated to wellbeing. ${ }^{30}$

Within the international literature, a large number of publications examine wellbeing issues in remote areas in the world. The relationship between transport and wellbeing in remote areas is also the object of a number of studies, particularly in the regional development industry. ${ }^{31}$

Currently, in remote Australia, access to transport is perceived as a fundamental way to avoiding ill-being; access to transport is necessary for accessing critically important services (such as health or administrative services) and for maintaining the lifeline of socio-cultural community connections that define the livelihoods of Australian Aboriginal and Torres Strait Islander remote communities active. From both perspectives, the lack of access to transport is a source of structural inequality in remote Aboriginal and Torres Strait Islander communities. ${ }^{32}$ Extrapolating on the wellbeing framework of Nguyen and Cairney, ${ }^{33}$ Table 1 presents some of the relationships between transport and wellbeing for people living in remote

\footnotetext{
${ }^{27}$ Australian Bureau of Statistics (ABS), The Health and Welfare of Australia's Aboriginal and Torres Strait Islander Peoples (ABS, Oct 2010); Australian Bureau of Statistics (ABS), Australian Social Trends, Aboriginal and Torres Strait Islander Peoples' Labour Force Outcomes (ABS, 2013); Australian Bureau of Statistics (ABS), 'Australian Social Trends: Exploring the Gap in Labour Market Outcomes for Aboriginal and Torres Strait Islander Peoples' (ABS, no. 4102.0, 2013). ${ }^{28}$ ABS, Framework for Measuring, above n 16; Productivity Commission, 'Disability Within the Indigenous Community' in Disability Care and Support, (Australian Government, Chpt 11, 2011).

${ }^{29}$ ABS, Framework for Measuring, above n 17.

${ }^{30}$ Biddle, above $\mathrm{n} 24$.

${ }^{31}$ G Fitzgerald, The Social Impacts of Poor Access to Transport in Rural New Zealand (NZ Transport. Agency Research Report 48, Wellington, NZ, 2012); P Starkey, ‘A Methodology for Rapid Assessment of Rural Transport Services’ (Working Paper No.87-A, World Bank, Washington, DC. US, (2007).

${ }^{32}$ Raicu et al, above $\mathrm{n} 10$.

${ }^{33}$ Nguyen and Cairney, above n 16.
} 
Aboriginal and Torres Strait Islander communities. This model will enable the identification of the contribution of transport factors to wellbeing by relating it to the results of two surveys, one on transport and the other on mobility.

Table 1: Relationships between transport and wellbeing framework for people living in remote Aboriginal and Torres Strait Islander communities

Community Access to extended kinship networks, community members, social events, shared and inclusive spaces (Memmott et al, 2006; Raicu et al, 2011). Mobility to avoid social conflict (Currie and Senbergs, 2007).

Culture

Access to emotional relationship with places of spiritual significance and people, connection to homelands is important (Nguyen and Cairney, 2013). Strong mobility dependency over maintaining cultural obligations and being able to fulfil different types of commitments (Currie and Senbergs 2007; Young and Doohan, 1989).

Education

Transport to access education services (Raicu et al, 2011).

Health

Access to health services and safe transport are essential (Helps et al, 2008). Environmental friendly transport and active transport are able to provide very significant benefits at a societal level (Clifford, Pearson, Franklin, Walker and Zosky, 2015; Thompson, Gifford and Thorpe, 2000) and a psychological one (Campbell, Burgess, Garnett and Wakerman, 2011).

Economic participation and Access to transport instrumental in economic participation in both customary economy and mainstream economy (Altman, 2010; ABS (Public Transport Access), 2010; Dockery, 2015) access to goods, meeting living standards and managing living costs (Biddle, 2011; Dockery and Colquhoun, 2012; Young and Doohan, 1989).

Empowerment Access to decision making situations, opportunities to live sustainably on country (Memmott et al, and governance 2013; Smith, 2004).

\section{Transport surveys}

Two surveys of Central Australian remote communities were conducted in 2014-2015; : one on mobility and the other on transport access. The surveys collected information on transport and mobility practices, and examined the perceived satisfaction and sustainability of transport. Additionally, participants in the survey expressed their views on transport issues.

The mobility survey asked questions about the last trips involving an overnight stay over a three-month period with origins and destinations. In 2014 and 2015, primary data about mobility was collected in 25 very remote communities. A total of 750 individuals living across Central Australia were involved in this process. $^{34}$

The transport survey investigated transport practices that took place in Lajamanu, Santa Teresa and Hermannsburg in Central Australia and involved 75 participants. A team of Aboriginal Community Researchers undertook the field work, conducting 25 surveys in each community (4-6\% of the population) using consent forms and in accordance with the code of practice of the Business Development Unit of Ninti One Ltd. ${ }^{35}$ Preferences for transport alternatives were examined in detail using questions related to perceived transport sustainability (safety, comfort and reliability of infrastructures, vehicles and services), recommendations to improve transport networks, vehicles and services and ratings of travelling conditions, and future transport alternatives (including non-transport solutions).

\section{Results}

Several findings pointed to the fact that people derive wellbeing from the experience of mobility - from the journey itself. According to Dockery, people are generally happy to travel: '36 per cent didn't mind going, 47 per cent felt good and 8 per cent very good about going'. ${ }^{36}$ Dockery's survey work was based on the conceptualisation of mobility as a means to access things that promote wellbeing, with a focus on attachment to country, culture and kinship networks as drivers of Aboriginal and Torres Strait Islander mobility and wellbeing. ${ }^{37}$ Indeed the results of both surveys reported that visiting friends and family, and doing shopping were the major reasons to travel (Figure 4).

\footnotetext{
${ }^{34}$ M Dockery, 'On the Move: A Key to Remote Australian Success' (Media Release, CRC-REP, Ninti One Limited, 2015).

${ }^{35}$ B Spandonide, 'Preferred Transport Futures in Remote Australia" (CRC-REP Working Paper CW, Alice Springs, 2015).

${ }^{36}$ Dockery, 'On the Move', above n 34.

${ }^{37}$ Ibid; Dockery, 'Reconceptualising mobility', above n 17; Dockery and Hampton, above n 25.
} 


\section{Travel purposes}

\section{$79 \%$ of trips}

to visit friends or family

\section{$\Longrightarrow 54 \%$ of trips}

to do some shopping

\section{$19 \%$ of trips}

to go to work

\section{[a] $18 \%$ of trips}

to go to the bank

\section{IIII $13 \%$ of trips}

to attend cultural events

Uj $11 \%$ of trips

to access medical services

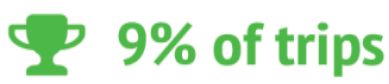

to attend sport events

Figure 4: Trip purposes in very remote Aboriginal Central Australian communities (Source: Spandonide, 2015)

Relating these findings to the wellbeing frameworks supports the contention that transport is important for achieving high levels of wellbeing by fulfilling the demand and aspirations for community interaction, economic participation, and empowerment and governance. Access to cultural activities and health services, however, responds to different time constraints, which demonstrates the complexity of specific areas of wellbeing and the unique characteristics of the associated transport demand. The research shows that travel is undertaken for a great variety of purposes. Figure 5 provides information about trip characteristics.

\section{Travel characteristics}

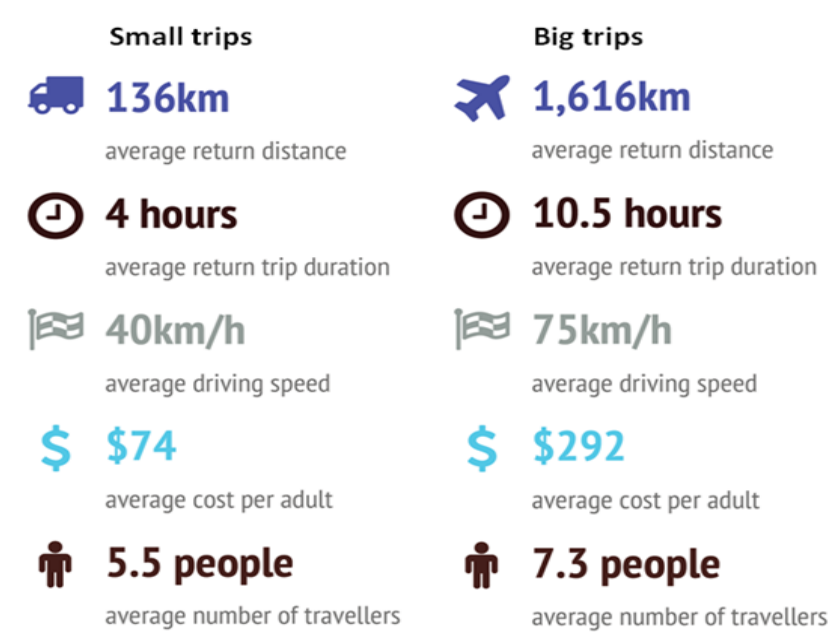

Figure 5: Trip characteristics in very remote Aboriginal Central Australian communities (Source: Spandonide, 2015)

In summary:

- People living in very remote Central Australian communities display a high level of local, regional and long distance mobility and undertake more than one small trip per day (with a portion of these trips allocated to travel to the nearest service centre) and more than one return big trip per month.

- This is remarkable considering the levels of transport disadvantage which affects a majority of Aboriginal people living in remote communities in Central Australia. 
- A majority of people perceived transport affordability and accessibility as the main limitations to sustaining their travelling needs but judged transport as being safe and reliable.

\section{Transport disadvantaged groups and ill-being in remote Australia}

Low-income people, females, youth/children and elderly, disabled people, people living in outer-urban or regional and remote communities, and people belonging to an ethnic minority are all more likely to experience transport disadvantage. ${ }^{38}$ These elements often operate in a cumulative way. For instance, people with disabilities experience a large number of barriers to travel and are more likely to be unemployed or to be on a lower income. ${ }^{39}$ For transport disadvantaged groups, prohibitive costs, low frequency and poor coverage of suitable transport result in a structural loss of independence and decreased liveability. ${ }^{40}$ There is much evidence of latent transport demand from transport disadvantaged groups at a national level. ${ }^{41}$

In remote Australia, transport disadvantaged groups are similar; however, the magnitude of disadvantage is different: over half of the population of very remote Australian communities is composed of Aboriginal and Torres Strait Islander people. In remote Aboriginal and Torres Strait Islander communities, low-income people, children or young adults, and people with disabilities are over-represented. Furthermore, while at a national level transport issues start to be more pronounced for age groups over 80 years, in remote Aboriginal and Torres Strait Islander communities, mobility issues are more prominent for age groups over $55 .^{42}$

As a result, over 75 per cent of the population in remote Aboriginal and Torres Strait Islander communities belong to four or more transport disadvantaged groups. An estimated total of 55000 people experience very advanced forms of transport disadvantage characterised by the combination of different structural access issues.

Poor infrastructures and equipment, insufficient and uncoordinated services and inappropriate transport regulations tend to increase travelling times and transport costs. ${ }^{43}$ In some specific areas, transport services have improved over the years. For instance, substantial transport resources have been developed for accessing health services even though significant inequalities still exist; ${ }^{44}$ as an example, the Purple House mobile dialysis truck is an example of best-practice.

A majority of remote Aboriginal and Torres Strait Islander communities are accessible only via unsealed roads. ${ }^{45}$ This requires the use of particularly robust and expensive vehicles. A majority of Aboriginal and Torres Strait Islander people living in remote communities can only afford to purchase conventional vehicles which are at the last stages of their lives. ${ }^{46}$ The average life span of vehicles is, therefore, particularly short with a majority of the cars not able to be used after six months to two and a half years. ${ }^{47}$

Low access to registered vehicles is also a structural challenge for the regional development of remote communities. Holcombe reported typical levels of 5-10 per cent of registered vehicles in remote Aboriginal communities $^{48}$ and Pleshet observed similar levels. ${ }^{49}$ The most recent data and observations from a

${ }^{38}$ J Dodson, B Gleeson and N Sipe, 'Transport Disadvantage and Social Status: A Review of Literature and Methods' Urban Policy Program Research Monograph (2004) 5.

39 J Evans and M White, 'A Review of Transport Resources for People with Disabilities: A State-of-the-Art Review' (ARRB Transport Research, Review Report 3, Verment South, Victoria, 1998); L Gething, 'Sources of Double Disadvantage for People with Disabilities Living in Remote and Rural in Australian Desert Aboriginal Development' The Rangeland Journal (1997) 30(1) 55; Productivity Commission, above n 27.

${ }^{40}$ Currie et al, above $\mathrm{n} 15$.

${ }^{41}$ Currie and Delbosc, above n 7; J Stanley, D Hensher, J Stanley, G Currie, W H Greene, and D Vella-Brodrick, Social Exclusion and the Value of Mobility (Institute of Transport and Logistics Studies, The Australian Key Centre in Transport and Logistics Management, The University of Sydney, 2010).

${ }^{42}$ Spandonide, above $\mathrm{n} 35$.

${ }^{43}$ J F Smoker, The Terra Nullius of Infrastructure : Roads to Remote Indigenous Towns (Curtin University, School of Humanities Curtin University of Sustainability Policy (CUSP), 2011).

${ }^{44}$ Department of Health Northern Territory, 'Review of the Patient Assistance Travel Scheme' (NT Government, 2013); NT Council of Social Service Inc, 'Cost of Living Report Tracking Changes in the Cost of Living, Particularly for Vulnerable and Disadvantaged Northern Territorians: The Cost of Transport in the Territory' (NT COSS, October 2013).

${ }^{45}$ Smoker, above $\mathrm{n} 43$

${ }^{46}$ D Young, 'The Life and Death of Cars: Private Vehicles on the Pitjantjatjara Lands South Australia' in D Miller (ed), Car Cultures (Berg Publishers, 2001) 35.

${ }^{47}$ Gerard, above $\mathrm{n} 1$.

${ }^{48}$ S Holcombe, 'Indigenous Australians and Transport: What can the NATSSIS tell us?' in B Hunter (ed), Assessing the Evidence on Indigenous Socioeconomic Outcomes: A Focus on the 2002 NATSISS (ANU E Press, 2006) 183. 
transport study conducted in three remote Aboriginal communities in Central Australia indicated that the situation was the same in $2015 .^{50}$

Access to public transport is another critical issue. Some new transport operators have started supplying a number of remote Aboriginal and Torres Strait Islander communities in Central Australia, but many Aboriginal and Torres Strait Islander communities in Western Australia and Queensland still have no access to regular public transport services. ${ }^{51}$

There is a lack of appropriate regional transport policy specific to remote Aboriginal and Torres Strait Islander communities. There are some recent improvements to increase the licensing of people living in remote communities. ${ }^{52}$ Fuel costs are particularly high in these communities and the situation has not changed over the last 30 years. ${ }^{53}$ Around 8 per cent of average income of those living in these remote communities is allocated to fuel costs with fuel taxes corresponding to about 3 per cent of the average income as opposed to less than 1 per cent nationally. ${ }^{54}$ These extra costs magnify business expenses at several levels of the supply chain, resulting in largely amplified living costs in remote communities - about double the national average for a typical basket of goods. ${ }^{55}$

A vast majority of people living in very remote Aboriginal and Torres Strait Islander communities experience financial hardships in their efforts to cover the essential transport expenses of registering and maintaining a vehicle, or purchasing a public transport ticket. ${ }^{56} \mathrm{~A}$ lack of appropriate concession policy across different transport services was highlighted in the responses of the transport access survey to the questions about perceived transport issues in remote Aboriginal Central Australian Communities (Figure 6).

\section{Perceived transport issues}

\section{× $31.5 \%$ of people}

do not have access to a vehicle

\section{$32 \%$ of people}

would like to register a vehicle

Figure 6: Perceived Transport Issues in Remote Aboriginal Central Australian Communities (Source: Spandonide, 2015)

Dockery and Hampton report that financial issues and poor transport access are the main barriers to transport, before cultural and family reasons (Figure 7). ${ }^{57}$

Moreover, in terms of transport access, subsequent layers of transport inequalities exist: for instance a number of gender transport needs have been reported (Figure 8), with generational differences also identified.

The different factors demonstrate the complexity of travelling activities and access to transport, and the links to different values; these are all considerations necessary for understanding how ill-being can be a consequence of poor transport practices. For example, when promoting culturally inclusive, accessible and safe transport, the different transport needs and access levels of gender and age groups also should be considered.

\footnotetext{
${ }^{49} \mathrm{~N}$ Pleshet, On the Move in Central Australia: Remote Transportation Update (Our Place 39, Centre for Appropriate Technology, CAT, 12-15, 2007).

50 Spandonide, 'Understanding Transport', above n 35.

${ }^{51} \mathrm{ABS}$, The Health and Welfare, above $\mathrm{n} 27$.

${ }^{52}$ Holcombe, above $\mathrm{n} 48$.

${ }^{53}$ G Crough and B Pritchard, Too Poor to Pay Tax? Aborigines and the Australian Taxation System (Central Land Council, Alice Springs, NT, 1991).

${ }^{54}$ NT Council of Social Services, above n 44.

${ }^{55}$ Department of Health NT, above n 44.

${ }^{56}$ Spandonide, 'Transport Systems', above n 35.

${ }^{57}$ Dockery and Hampton, above n 24
} 


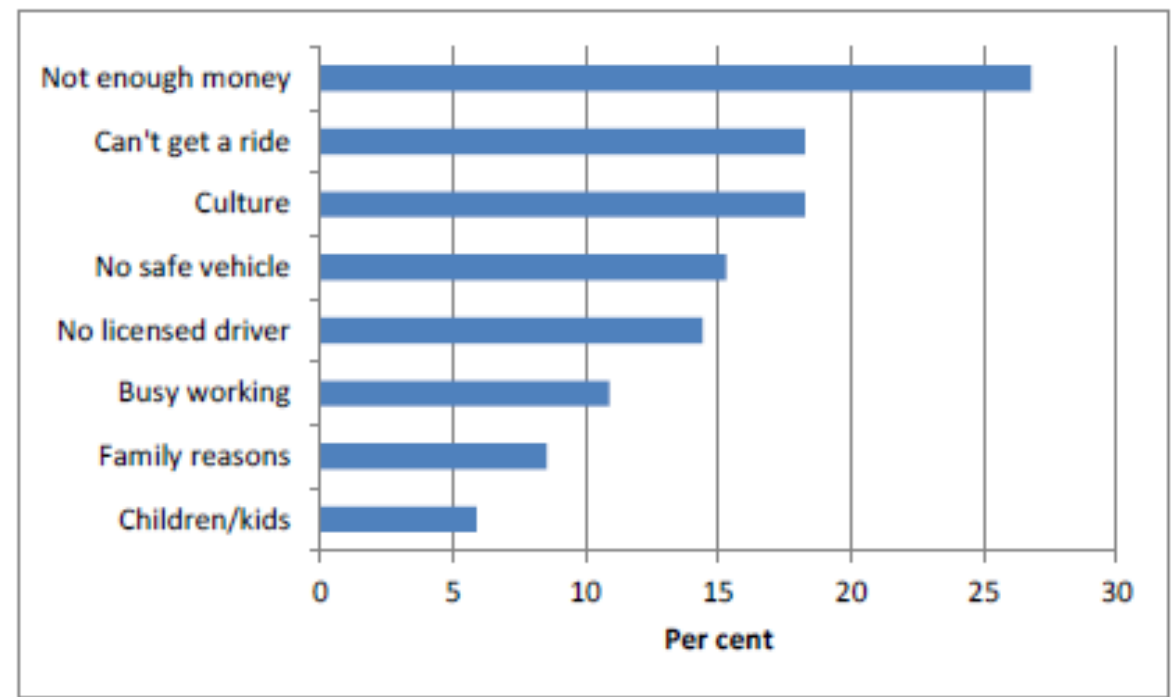

Figure 7: What stops you travelling? (People who wanted to make a trip but could not in the past 12 months)

\section{Gender preference specificities}

\section{travel twice more}

for education purposes or to go to the

bank

\section{隹 travel twice more}

as car passengers or in a bus

\section{travel twice more}

\section{to look for work, go to Centrelink and attend sport events}

\section{in travel twice more}

driving cars, walking, or by plane

(source: Dockery and Hampton, 2015)

Figure 8: Gender preference specificities in remote Aboriginal Central Australian communities (Source: Spandonide, 2015)

\section{Appropriate transport to foster wellbeing in remote communities}

Aboriginal and Torres Strait Islander people living in remote communities have organised several innovative transport systems. For instance, car sharing and lift taking practices respond to the critical shortage of transport vehicles and services. As a result, average car occupancy rates are among the highest in the world. ${ }^{58}$ Bush mechanic and advanced eco-driving practices have also been developed.

In terms of transport safety, Brice (2000) reports that the relative road casualty rate of Aboriginal and Torres Strait Islander people is three times higher the rate of non-Aboriginal and Torres Strait Islander people. ${ }^{59}$ However, the urban NT Aboriginal and Torres Strait Islander population represents just over 10 per cent of the total NT urban population ${ }^{60}$ but 60 per cent of road casualties occurring in urban areas involve Aboriginal and Torres Strait Islander people. That is, there is some evidence indicating that transport-related accidents affect Aboriginal and Torres Strait Islander people much more often in nonremote locations. The rural NT Aboriginal population, representing around 50 per cent of the rural area population, accounts for less than 40 per cent of road fatalities. Post-crash care factors include lack of

\footnotetext{
${ }^{58}$ Holyoak et al, above n 3.

${ }^{59} \mathrm{G}$ Brice, Australian Indigenous Road Safety: A Critical Review and Research Report, with Special Reference to South Australia, other Indigenous Populations, and Countermeasures to Reduce Road Trauma (Aboriginal Health Council of South Australia Transport, Walkerville, 2000).

${ }^{60}$ School for Social and Policy Research, Population Studies Research Brief, (Charles Darwin University, 2008).
} 
access to care and lack of insurance. ${ }^{61}$ In very remote areas, non-Aboriginal and Torres Strait Islander people are over-represented in road casualty rates and as likely to be involved in an accident on remote and rural roads than Aboriginal and Torres strait Islander people. The statistics published indicate that over the last ten years, the road fatality rate for Aboriginal and Torres Strait Islander people has decreased while the road fatality rate for non- Aboriginal and Torres Strait Islander people has increased. ${ }^{62}$

Table 2 summarises some areas of research that could lead to improved transport liveability and social sustainability in remote Aboriginal and Torres Strait Islander communities.

Table 2: Areas of research for improved transport liveability and social sustainability in remote Aboriginal and Torres Strait Islander communities.

\begin{tabular}{|c|c|c|}
\hline Categories & Innovation & Benefit \\
\hline $\begin{array}{l}\text { Transport } \\
\text { infrastructures }\end{array}$ & $\begin{array}{l}\text { One lane roads, solar roads, new } \\
\text { pavements, community road } \\
\text { maintenance projects }\end{array}$ & $\begin{array}{l}\text { Improving physical access, more affordable and inclusive } \\
\text { infrastructures, encouraging economic participation } \\
\text { opportunities, reducing emissions }\end{array}$ \\
\hline $\begin{array}{l}\text { Transport } \\
\text { vehicles }\end{array}$ & $\begin{array}{l}\text { Vehicle sharing, low-cost hybrid } \\
\text { four wheel drive, mobile mechanics }\end{array}$ & $\begin{array}{l}\text { Improving physical access, more affordable transport, } \\
\text { encouraging economic participation opportunities, reducing } \\
\text { emissions }\end{array}$ \\
\hline Public transport & $\begin{array}{l}\text { Frequent door to door services, } \\
\text { community transport }\end{array}$ & $\begin{array}{l}\text { Improving physical access, encouraging economic participation } \\
\text { opportunities, reducing emissions }\end{array}$ \\
\hline $\begin{array}{l}\text { Other transport } \\
\text { services }\end{array}$ & $\begin{array}{l}\text { Discounted individual and group } \\
\text { travel ticketing }\end{array}$ & $\begin{array}{l}\text { Improving physical access, more affordable and inclusive } \\
\text { services, reducing travel needs, encouraging travelling, } \\
\text { reducing emissions }\end{array}$ \\
\hline Renewable fuel & Electric mobility & More affordable transport, reducing emissions \\
\hline Transport policy & $\begin{array}{l}\text { Integrated planning, tax } \\
\text { (registration, license, fuel) }\end{array}$ & More affordable transport, encouraging travelling \\
\hline $\begin{array}{l}\text { Non-transport } \\
\text { solutions }\end{array}$ & $\begin{array}{l}\text { Communication services, services in } \\
\text { communities }\end{array}$ & Reducing travel needs, reducing emissions \\
\hline Active transport & $\begin{array}{l}\text { Green waves, culturally safe } \\
\text { planning and payment }\end{array}$ & $\begin{array}{l}\text { Improving physical access, more affordable and inclusive } \\
\text { services, reducing travel needs, encouraging travelling, } \\
\text { reducing emissions }\end{array}$ \\
\hline
\end{tabular}

Some innovative social responses display a number of characteristics of the currently booming sharing economy: sharing vehicles, recycling equipment and encouraging positive relationships are key drivers of transport activities in the bush, and contribute towards enhancing the wellbeing of people living in remote Aboriginal and Torres Strait Islander communities. These transport systems also incorporate specific sociocultural elements that allow extending transport access in Aboriginal and Torres Strait Islander communities.

Other transport initiatives could be developed. A portfolio of general and targeted transport initiatives has been identified from the transport survey, including infrastructure, private vehicle and public transport access improvements, integrated transport, sharing transport resources, innovative policy frameworks and non-transport solutions, as well as high and low-tech technical innovations.

As transport operating in remote communities is highly capital intensive, transport industry stakeholders (for both freight and public transport services) would greatly benefit from enhanced coordination to better use resources and connection and cross-modal integration. Remote service providers could also benefit from sharing transport resources and capitalising on the existing practices in communities to develop transport sharing schemes for community development projects.

Innovative policy frameworks could include providing additional low cost transport solutions which would contribute to decreasing living costs, supporting active transport (including non-motorised forms of transport involving physical activity, such as walking and cycling), and taking steps towards a long-term future of renewable energy-based transport. Therefore, there is a need for developing a culturally appropriate framework for fast-tracking the adoption of new technologies and innovations in the transport sector.

\footnotetext{
${ }^{61} \mathrm{~N}$ Thomson, I Krom and K Ride, Summary of Road Safety Among Indigenous Peoples (Australian Indigenous HealthlnfoNet, 2009).

${ }^{62}$ Department of Transport, Northern Territory Road Injury Statistical Summary (NT Government, 2013).
} 


\section{Discussion}

In the transport survey, a clear majority of respondents expressed an aspiration for purchasing a public transport ticket, registering a vehicle, purchasing fuel or undertaking vehicle repairs (Figure 9).

\section{What would people do with more disposable income?}

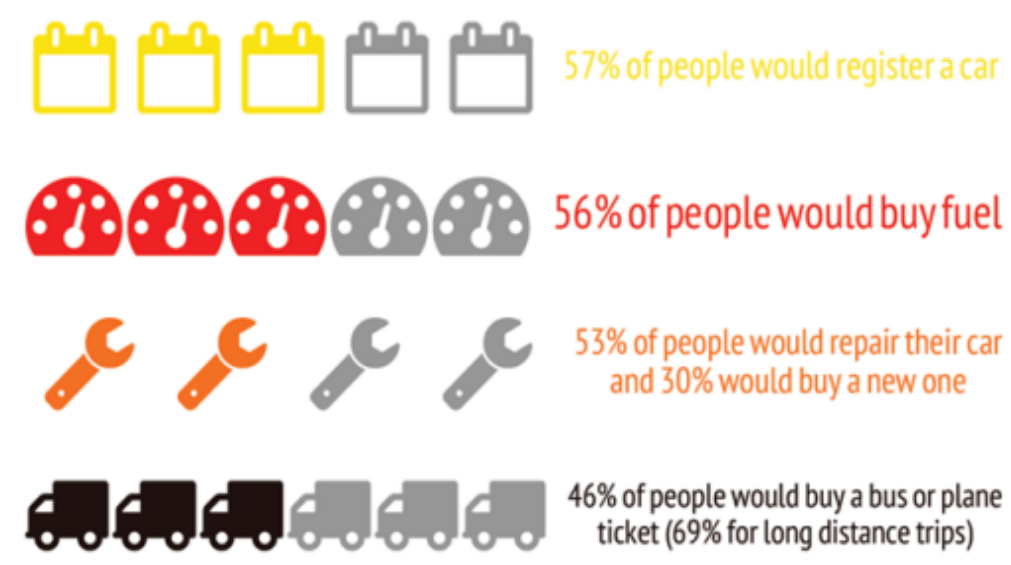

Figure 9: Transport issues in Central Australian Aboriginal communities: What would people do with more disposable income?

(Source: Spandonide, 2015)

It is a remarkable finding that, despite a low level of access to public transport (only half of remote Aboriginal and Torres Strait Islander communities in Australia has access to public transport, and the public transport network in Central Australia is not well connected, have a limited coverage, and is based on very low frequencies), public transport incorporates the highest latent transport demand. This illustrates the potential for more appropriate public transport systems in remote Australian Aboriginal and Torres Strait Islander communities.

An inclusive growth of the public transport industry will have to integrate new pricing technologies to increase the convenience of using public transport. The success of the ticketing system of the Centre Bush Bus and the Bodhi Bus in Central Australia (with direct charging from Centrelink accounts) illustrates the importance of convenient payment systems. Moreover, improved public transport access, frequency and pricing would lead to great co-benefits in terms of social sustainability. Despite the benefits, public transport adequacy is decreasing in rural Australia. ${ }^{63}$ For decades there have been reports of transport cost discrimination and abuses, with overcharging practices in different transport sectors (for purchasing vehicles and maintenance services but also for taxi and bus services). An increased price transparency could be achieved by the use of modern digital technologies and could allow a greater inclusiveness of Aboriginal and Torres Strait Islander people living in remote communities. Having more affordable public transport contributes to more active transport and less emission generation.

From the results of the surveys discussed above, it is possible to extrapolate the potential appropriateness and positive impacts in terms of wellbeing from a range of transport projects and initiatives. In Table 3 the different transport innovations have been plotted in a matrix within the wellbeing framework.

The table presents key conclusions/recommendations. Improving transport infrastructures might be perceived as an obvious but costly priority but other transport alternatives might well be more cost effective and appropriate as ways to improve wellbeing in remote Aboriginal and Torres Strait communities.

${ }^{63}$ Morton and Edwards, above n 20. 
Table 3: Matrix of transport innovations related to the wellbeing framework

\begin{tabular}{|c|c|c|c|c|c|c|}
\hline Transport innovations & Community & Education & Health & Culture & $\begin{array}{c}\text { Economic } \\
\text { participation / } \\
\text { living standards }\end{array}$ & $\begin{array}{l}\text { Empowerment } \\
\text { and governance }\end{array}$ \\
\hline $\begin{array}{l}\text { One lane sealed vs } \\
\text { double unsealed }\end{array}$ & $x$ & $x$ & $x$ & $x$ & $\mathbf{x}$ & \\
\hline Solar roads & & & & & $x$ & \\
\hline New pavements & $x$ & $x$ & $x$ & $x$ & $x$ & \\
\hline $\begin{array}{l}\text { Community road } \\
\text { maintenance }\end{array}$ & $x$ & & & & $\mathbf{x}$ & $x$ \\
\hline Vehicle sharing (govt) & & $x$ & $x$ & & $x$ & $x$ \\
\hline $\begin{array}{l}\text { Low-cost hybrid four } \\
\text { wheel drive }\end{array}$ & $x$ & $x$ & $x$ & $x$ & $x$ & $x$ \\
\hline $\begin{array}{l}\text { Mobile mechanic } \\
\text { services }\end{array}$ & $x$ & $x$ & $x$ & $x$ & $x$ & $x$ \\
\hline $\begin{array}{l}\text { Frequent door to door } \\
\text { services }\end{array}$ & $x$ & $x$ & & & $x$ & \\
\hline Discounted ticketing & $x$ & $x$ & & & $x$ & \\
\hline Community transport & $x$ & $x$ & $x$ & $x$ & $x$ & $x$ \\
\hline Electric mobility & & & & & $x$ & \\
\hline Integrated planning & $x$ & $x$ & $x$ & $x$ & $x$ & \\
\hline $\begin{array}{l}\text { Concession } \\
\text { registration/license }\end{array}$ & $x$ & $x$ & $x$ & $x$ & $x$ & $x$ \\
\hline Fuel excise & $x$ & $x$ & $x$ & $x$ & $x$ & \\
\hline Communication services & $x$ & $x$ & $x$ & $x$ & $x$ & $x$ \\
\hline Services in communities & $x$ & & & & $x$ & $x$ \\
\hline Active transport & $x$ & & $x$ & $x$ & $x$ & $x$ \\
\hline Culturally safe planning & $x$ & $x$ & $x$ & $x$ & $x$ & $x$ \\
\hline Tolls and road subsidies & & & $\mathrm{x}$ & & $\mathrm{x}$ & $x$ \\
\hline
\end{tabular}

The transport initiatives which would have the broadest positive impacts in terms of wellbeing are providing concessions for registrations and licenses, mobile mechanic services, access to low cost four wheel drive efficient vehicles, and appropriate community transport systems, as well as two non-transport solutions: operating with culturally safe and inclusive planning standards, and supporting projects which would improve access to communication. The advantage of these alternatives consists of the particularly low level of entry costs and a relatively high level of cost-effectiveness.

Non-transport innovations are also essential for improving transport efficiency, reducing transport needs (which would be particularly appropriate in the context of the very high latent transport demand in remote communities) and reducing transport emissions. This includes developing additional local services for remote Aboriginal and Torres Strait Islander communities, encouraging local production of goods, promoting on-line access to services and information, providing appropriate maintenance services within communities and providing appropriate services for people with disabilities (Figure 10).

When asked about the options that would effectively reduce transport needs, participants of the transport survey also mentioned community transport services and special services for mobility impaired people. This is a reminder that transport initiatives targeting the specific inaccessibility of the most disadvantaged groups of people at a community level is particularly important. Indeed the framework does not encapsulate the complexity of wider impacts of ill-being at a community level caused by the inability of the most disadvantaged sub-categories of people living in remote Aboriginal and Torres Strait Islander communities to access transport, nor does it capture the extent of the wider benefits that transport innovations could provide at a societal level. 


\section{Travel reduction options}

\section{$54 \%$ of participants}

would stay more in their community

with more services available locally

\section{$41 \%$ of participants}

would stay more in their community with a more affordable goods delivery

\section{$37 \%$ of participants}

would stay more in their community with community mechanics

\section{$33.5 \%$ of participants} would stay more in their community with a community bus

\section{$17 \%$ of participants}

would stay more in their community with better internet access

\section{\& $14.5 \%$ of participants}

\author{
would travel less with more local \\ transport special services for disabled, \\ young and elderly people
}

Figure 10: Travel reduction options for people living in remote Aboriginal Central Australian communities (Source: Spandonide, 2014)

For instance, while the relative distances between remote communities and large service centres seem to exclude the use of non-motorised or low powered transport, active transport is still relevant in remote communities for local transportation. Active transport costs less public and private money in terms of infrastructure investment and is generally more inclusive of groups of mobility-impaired people.

Encouraging active transport can also lead to substantial benefits in reducing externalities. Health cost benefits are obviously significant, both in terms of direct positive impacts of increased physical activity and in terms of reduced local pollution. ${ }^{64}$ Pollution from transport activities claims more lives each year than road accidents. ${ }^{65}$ The amount of $\mathrm{CO}_{2}$ emission reduction delivered by active transport compared to motorised transportation significantly differs between different studies, ranging from $1.5^{66}$ to around $30 .{ }^{67}$ The variations can be explained by the distance differences in the relative baseline scenarios: walking and cycling most often occur over shorter distances ${ }^{68}$ and are not able to effectively replace the needs for motorised transport for long distance trips. Even then, local trips represent 15-20 per cent of the annual distance travelled and switching to active transport for local trips still provides a 20-30 per cent reduction both in GHG emissions and carbon footprint.

This is further justified by the fact that (as shown in Table 3 ) integrated planning and cross-agencies collaboration and active transport would also have broad positive impacts. These types of transport alternatives perform as well in terms of appropriate ways to enhance wellbeing as do low-cost road projects or a fuel excise policy, and would be able to be implemented with substantially less capital investment.

Furthermore, the social benefits of increased disposable incomes at a community level in a context of durable economic disadvantage should not be underestimated. Further research is needed to understand the line-up and the scale of the multiple benefits at a community and an interpersonal level of active transport in terms of the cultural appropriateness, socio-cultural engagement and quality of life ${ }^{69}$ As the mutually beneficial outcomes derived from reduced emissions and increased uses of active transport are shared among the society, there is robust scope for providing financial incentives and high quality infrastructures for developing active transport in large remote communities.

\footnotetext{
${ }^{64}$ C G Pooley et al, 'Can Increased Walking and Cycling Really Contribute to the Reduction of Transport-Related Carbon Emissions?' in T Ryley and L Chapman (eds), Transport and Climate Change (Emerald, Bingley, 2012).

${ }^{65}$ Bureau of Transport and Regional Economics, 'Health Impacts of Transport Emissions in Australia: Economic Costs' (Australian Government, Canberra, ACT, 2005); J Lelieveld, J S Evans, M Fnais, D Giannadaki and A Pozzer, 'The Contribution of Outdoor Air Pollution Sources to Premature Mortality on a Global Scale' Nature (2015) 525 (7569) 367.

${ }^{66}$ A Duffy and R Crawford, 'The Effects of Physical Activity on Greenhouse Gas Emissions for Common Transport Modes in European Countries' Transportation Research Part D: Transport and Environment (2013) 19 (March) 13.

${ }^{67}$ Camden Council, Carbon Emissions per Transport Type (Clear Zone Partnership, 2009).

${ }^{68}$ C Mason, 'Transport and Health: En Route to a Healthier Australia?' Medical Journal of Australia (2000) 172230.

${ }^{69}$ C Gray, R Macniven and N Thomson, 'Review of Physical Activity Among Indigenous People' Australian Indigenous Health Bulletin (2013) 13 (3).
} 
Using the same logic, accelerating the technological readiness of remote communities could have a number of significant long-term sustainability benefits. With increased battery capacity and renewable energy generation facilities in remote communities, an integrated energy system could be created via the use of electric driverless shared vehicles as potentially mobile energy storage components. Such a system could considerably improve off-the-grid livelihoods and effectively reduce the costs associated with living in very remote locations.

Work practices are likely to become less place-independent as the general trend towards ultra-mobility develops around the world over the next 50 years. Moreover, future technological innovations are anticipated to deliver significant progress in terms of wellbeing in the transport industry itself. ${ }^{70} \mathrm{~A}$ broad reflection on future sustainable remote livelihoods could include access to goods and services, employment, enhanced social capital, socio-cultural activities, and has to integrate safer and more affordable and inclusive means of transportation. ${ }^{71}$

This article highlighted the importance of transport access for remote ill-being and wellbeing. Having good appropriate transport access to country allows fulfilment of the aspiration to care for country, which is one of the most positive connections between people and places and is highly related to level of wellbeing. By establishing a link between different multi-disciplinary community-based research programs and combining some of the key findings, this research informs on the type of policy that might be suitable for remote Aboriginal and Torres Strait Islander communities: the study confirms that long-term low wellbeing levels tend to cause exponential costs and externalities, ${ }^{72}$ and that an effort to plan and develop a comprehensive set of well-designed cost-effective remote transport resources at a systemic level is necessary to sustain the exceptional and singular socio-cultural potential that defines each of these communities. There is also a strong relevance to other remote regional areas in the world where ethnic minorities are confronted with similar types of transport inequality issues because their transport policies and systems are not appropriately designed.

\section{REFERENCES}

Australian Bureau of Statistics (ABS), 'Framework for Measuring Wellbeing: Aboriginal and Torres Strait Islander Peoples' (4703.0, 2010).

Australian Bureau of Statistics (ABS), Aboriginal and Torres Strait Islander People Public Transport Access (ABS, 2010)

Australian Bureau of Statistics (ABS), The Health and Welfare of Australia's Aboriginal and Torres Strait Islander Peoples (ABS, Oct 2010)

Australian Bureau of Statistics (ABS), Framework for Measuring, above n 16; Productivity Commission, 'Disability Within the Indigenous Community' in Disability Care and Support, (Australian Government, Chpt 11, 2011).

Australian Bureau of Statistics (ABS), 'Australian Social Trends: Exploring the Gap in Labour Market Outcomes for Aboriginal and Torres Strait Islander Peoples’ (ABS, no. 4102.0, 2013).

Australian Bureau of Statistics (ABS), Australian Social Trends, Aboriginal and Torres Strait Islander Peoples' Labour Force Outcomes (ABS, 2013)

Biddle, N, 'Measures of Indigenous Wellbeing and Their Determinants Across the Lifecourse' in N Biddle (ed), Income, Work and Indigenous Livelihoods (Australian National University. Centre for Aboriginal Economic Policy Research, Lecture 5, 2011).

Biddle, N, J Taylor and M Yap, 'Indigenous Participation in Regional Labour Markets, 2001-06' ( Centre for Aboriginal Economic Policy Research (CAEPR), ACT, Caepr Discussion Paper No. 288, 2008)

Bishop, P, 'Off Road: Four-Wheel Drive and the Sense of Place' Environment and Planning D: Society and Space (1996) 14(3) 257. https://doi.org/10.1068/d140257

\footnotetext{
${ }^{70}$ L Mason, A Lederwasch, T Prior and D Giurco, 'Vision 2040 Mining, Minerals and Innovation Starting a National Conversation about Sustainable Mineral Production (Institute for Sustainable Futures, UTS, Consultation Paper, prepared for CSIRO Minerals Down Under Flagship, Sydney, NSW, May 2011).

${ }^{71}$ A Goller, Picture the Future of Mobility (Siemens, Australia, 2011).

72 T Rath and J Harter, (2010), The Economics of Wellbeing (Gallup, 2010).
} 
Brice, G, Australian Indigenous Road Safety: A Critical Review and Research Report, with Special Reference to South Australia, other Indigenous Populations, and Countermeasures to Reduce Road Trauma (Aboriginal Health Council of South Australia Transport, Walkerville, 2000).

Bureau of Transport and Regional Economics, 'Health Impacts of Transport Emissions in Australia: Economic Costs’ (Australian Government, Canberra, ACT, 2005)

Camden Council, Carbon Emissions per Transport Type (Clear Zone Partnership, 2009).

Costanza, R, and B C Patten, 'Defining and Predicting Sustainability' Ecological Economics (1995) 15(3) 193 https://doi.org/10.1016/0921-8009(95)00048-8

Crough, G, and B Pritchard, Too Poor to Pay Tax? Aborigines and the Australian Taxation System (Central Land Council, Alice Springs, NT, 1991).

Currie, G, and A Delbosc, 'Exploring Transport Disadvantage, Social Exclusion and Well-Being in Spatial Context', (Paper presented at World Congess on Transport Research, 12 ${ }^{\text {th }}$, Lisbon, Portugal, 2010).

Currie, G, J Stanley and J Stanley, No Way To Go: Transportation and Social Disadvantage in Australian Communities (Monash University ePress, 2007).

Currie,G, and Z Senbergs, 'Indigenous Communities: Transport Disadvantage and Aboriginal Communities' in Graham Currie, Janet Stanley and John Stanley (eds), No Way to Go: Transport and Social Disadvantage in Australian Communities (Monash University Press, Melbourne, 2007), 1-9,12.

Department of Health Northern Territory, 'Review of the Patient Assistance Travel Scheme' (NT Government, 2013)

Department of Transport, Northern Territory Road Injury Statistical Summary (NT Government, 2013).

Dockery, M, 'On the Move: A Key to Remote Australian Success' (Media Release, CRC-REP, Ninti One Limited, 2015).

Dockery, M, 'Reconceptualising Mobility for Aboriginal and Torres Strait Islander Australians' (Working Paper CW015, CRC-REP, Alice Springs, 2014).

Dodson, J, B Gleeson and N Sipe, 'Transport Disadvantage and Social Status: A Review of Literature and Methods' Urban Policy Program Research Monograph (2004) 5.

Duffy, A, and R Crawford, 'The Effects of Physical Activity on Greenhouse Gas Emissions for Common Transport Modes in European Countries' Transportation Research Part D: Transport and Environment (2013) 19 (March) 13. https://doi.org/10.1016/j.trd.2012.09.005

Evans, J, and M White, 'A Review of Transport Resources for People with Disabilities: A State-of-the-Art Review’ (ARRB Transport Research, Review Report 3, Verment South, Victoria, 1998

Finlayson, J, and A Auld, Shoe or Stew? Balancing Wants and Needs in Indigenous Households: A Study of Appropriate Income Support Payments and Policies for Families (Australian National University - Centre for Aboriginal Economic Policy Research, Canberra, ACT, 1999).

Fitzgerald, G, The Social Impacts of Poor Access to Transport in Rural New Zealand (NZ Transport. Agency Research Report 48, Wellington, NZ, 2012)

Fogarty, W, ““You got any Truck?” Vehicles and Decentralised Mobile Service-Provision in Remote Indigenous Australia', (Centre for Aboriginal Economic Policy Research (CAEPR), ACT, Working Paper No. 30/2005, 2005).

Gerard, G, "Everyone will be Jealous for that Mutika", Mankind (1989) 19(2) 95; R Lawrence, 'Motorised Transportation in Remote Aboriginal Australia' Australian Aboriginal Studies (1991) 262.

Gething, L, 'Sources of Double Disadvantage for People with Disabilities Living in Remote and Rural in Australian Desert Aboriginal Development' The Rangeland Journal (1997) 30(1) 55.

Goller, A, Picture the Future of Mobility (Siemens, Australia, 2011).

Gray, C, R Macniven and N Thomson, 'Review of Physical Activity Among Indigenous People' Australian Indigenous Health Bulletin (2013) 13 (3). 
Headey, B, E Holmström and A Wearing, 'Well-Being and Ill-Being: Different Dimensions?' Social Indicators Research (1984), 14(2) 115. https://doi.org/10.1007/BF00293406

Holcombe, S, 'Indigenous Australians and Transport: What can the NATSSIS tell us?' in B Hunter (ed), Assessing the Evidence on Indigenous Socioeconomic Outcomes: A Focus on the 2002 NATSISS (ANU E Press, 2006) 183.

Holyoak, N, B Spandonide, B Stazic and R Zito, (2016), 'Travelling in Remote Australia Might Come a Gutsa: An Extreme Case of Transport Carbon Vulnerability’ Adelaide.

Kinfu, Y, Spatial Mobility Among Indigenous Australians: Patterns and Determinants (ANU Demography and Sociology Program, Research School of Social Sciences, Canberra, 2005)

Lelieveld, J, J S Evans, M Fnais, D Giannadaki and A Pozzer, 'The Contribution of Outdoor Air Pollution Sources to Premature Mortality on a Global Scale’ Nature (2015) 525 (7569) 367.

https://doi.org/10.1038/nature15371

Litman, T, Transportation Cost and Benefit Analysis II (Victoria Transport Policy Institute Canada, 2013)

Litman, T,' Well Measured: Developing Indicators for Sustainable and Livable Transport Planning' (Victoria Transport Policy Institute, 2016)

Litman, T, 'Evaluating Transportation Equity: Guidance for Incorporating Distributional Impacts in Transportation Planning’ (Victoria Transport Policy Institute, 2017).

Litman, T, and E Doherty, Transportation Cost and Benefit Analysis, Techniques, Estimates and Implications (Victoria Transport Policy Institute, Canada, 2011).

Magee, L, A Scerri, P James, J Thom, L Padgham, S Hickmottt, H Deng and F Cahill, 'Reframing Social Sustainability Reporting: Towards an Engaged Approach' in Environment, Development and Sustainability: A multidisciplinary Approach to the Theory and Practice of Sustainable Development (2013) 15(1) 225.

Mason, C, 'Transport and Health: En Route to a Healthier Australia?' Medical Journal of Australia (2000) 172230.

Mason, L, A Lederwasch, T Prior and D Giurco, 'Vision 2040 Mining, Minerals and Innovation Starting a National Conversation about Sustainable Mineral Production (Institute for Sustainable Futures, UTS, Consultation Paper, prepared for CSIRO Minerals Down Under Flagship, Sydney, NSW, May 2011).

Morton, A, and L Edwards, Community Wellbeing Indicators: Measures for Local Government (Australian Centre of Excellence for Local Government, University of Technology, Sydney, NSW, 2013).

Nguyen, O K, and S Cairney, Literature Review of the Interplay between Education, Employment, Health and Wellbeing for Aboriginal and Torres Strait Islander People in Remote Areas Working Towards an Aboriginal and Torres Strait Islander Wellbeing Framework (Ninti One Limited, Alice Springs, 2013).

NT Council of Social Service Inc, 'Cost of Living Report Tracking Changes in the Cost of Living, Particularly for Vulnerable and Disadvantaged Northern Territorians: The Cost of Transport in the Territory' (NT COSS, October 2013).

Nutley, S, 'Indicators of Transport and Accessibility Problems in Rural Australia' Journal of Transport Geography (2003) 11(1) 55. https://doi.org/10.1016/S0966-6923(02)00052-2

Pleshet, N, On the Move in Central Australia: Remote Transportation Update (Our Place 39, Centre for Appropriate Technology, CAT, 12-15, 2007).

Pooley, C G, et al, 'Can Increased Walking and Cycling Really Contribute to the Reduction of TransportRelated Carbon Emissions?' in T Ryley and L Chapman (eds), Transport and Climate Change (Emerald , Bingley, 2012).

Raicu, R, M Taylor, L Meng and G Currie, Scoping Study on Regional Transport in Desert Australia (Ninti One Limited, Alice Springs, 2011).

Rath, R, and J Harter, (2010), The Economics of Wellbeing (Gallup, 2010).

School for Social and Policy Research, Population Studies Research Brief, (Charles Darwin University, 2008). 
Smoker, J F, The Terra Nullius of Infrastructure : Roads to Remote Indigenous Towns (Curtin University, School of Humanities Curtin University of Sustainability Policy (CUSP), 2011).

Spandonide, B, 'Preferred Transport Futures in Remote Australia" (CRC-REP Working Paper CW, Alice Springs, 2015).

Spandonide, B, 'Understanding Transport Costs in Remote Australia' International Journal of Transport Economics (2016) XLIII.

Spandonide, B, Transport Systems in Remote Australia: Transport Costs in Remote Communities (Ninti One Limited, Alice Springs. 2014).

Stanley, J, D Hensher, J Stanley, G Currie, W H Greene, and D Vella-Brodrick, Social Exclusion and the Value of Mobility (Institute of Transport and Logistics Studies, The Australian Key Centre in Transport and Logistics Management, The University of Sydney, 2010).

Starkey, P, ‘A Methodology for Rapid Assessment of Rural Transport Services’ (Working Paper No.87-A, World Bank, Washington, DC. US, (2007).

Starkey, P, S Ellis, J Hine and A Ternel, Improving Rural Mobility: Options for Developing Motorized and Nonmotorized Transport in Rural Areas (World Bank, 2002).

Taylor, A, and B Prideaux, "Profiling Four Wheel Drive Tourism Markets for Desert Australia", Journal of Vacation Marketing, 14(1) 71.

Taylor, J, 'The Spatial Context of Indigenous Service Delivery’ (Centre for Aboriginal Economic Policy Research (CAEPR), ACT, CAEPR Working Paper No. 16 2002).

Thomson, N, I Krom and K Ride, Summary of Road Safety Among Indigenous Peoples (Australian Indigenous HealthInfoNet, 2009).

Young, D, 'The Life and Death of Cars: Private Vehicles on the Pitjantjatjara Lands South Australia' in D Miller (ed), Car Cultures (Berg Publishers, 2001) 35. 